\title{
Creating, maintaining and questioning (hetero)relational normality in narratives about vaginal reconstruction
}

\author{
Lisa Guntram
}

Journal Article

\section{Tweet}

N.B.: When citing this work, cite the original article.

Original Publication:

Lisa Guntram , Creating, maintaining and questioning (hetero)relational normality in narratives about vaginal reconstruction, Feminist Theory, 2013. 14(1), pp.105-121.

http://dx.doi.org/10.1177/1464700112468573

Copyright: SAGE Publications (UK and US)

http://www.uk.sagepub.com/home.nav

Postprint available at: Linköping University Electronic Press

http://urn.kb.se/resolve?urn=urn:nbn:se:liu:diva-104853

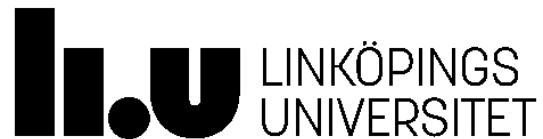




\title{
Creating, maintaining and questioning (hetero)relational normality in narratives about vaginal reconstruction
}

\author{
Lisa Guntram
}

Post print

\section{Please cite the original reference}

Guntram, L., 2013. Creating, maintaining and questioning (hetero)relational normality in narratives about vaginal reconstruction. Feminist Theory 14, 105-121.

doi:10.1177/1464700112468573

\begin{abstract}
Analyzing 10 interviews with women diagnosed with and treated for congenital absence of the vagina, this article theorises the notion of ideal (hetero)relational normality. It explores how the women negotiate, relate to and challenge this notion and examines the normative and bodily work that it calls for in my case study. The article specifically underscores the corporeal dimension of (hetero)relational normality. I argue that this notion of normality shapes the women's bodies through medical interventions, while concurrently being reinforced through the corporeal shapings that the women undergo. That is, the corporeal shapings consolidate enacted norms concerning heterosexuality and form understandings of female and male bodies. The analysis also reveals how the women nevertheless find ways to re-negotiate and question the notion of ideal (hetero)relational normality and its intertwinement with medical practice. The article contributes both to the critical examination of genital surgery and to feminist discussion of how to critically examine heterosexuality without rejecting it. Furthermore it provides a deeper understanding of how medical interventions designed to create a vagina or dilate a vagina considered 'too small' (i.e. vaginal reconstruction) are made meaningful by the women affected.
\end{abstract}


Keywords: normality, disordered sex development, young women, vaginal reconstruction, heterosexuality, narrative, vaginal agenesis

Corresponding author: Lisa Guntram, Department of Medical and Health Sciences, Linköping University, Sweden.

Email: lisa.guntram@liu.se

Being told, as a teenage girl, that you have neither a uterus nor a vagina can be a shocking experience. It may overthrow beliefs about one's body and expectations that previously have been taken for granted, and it may evoke questions regarding female embodiment, relationships and sexuality (Zeiler and Guntram forthcoming; Holt and Slade, 2003). This article takes its vantage-point from 10 in-depth interviews with women who in their teens became aware that they had no vagina or only parts of one. In line with Karkazis (2008), my intention is neither to dismiss women's treatment decisions nor to condemn treatment practices. I do not figure my interviewees as dupes of a heterosexist two-sex system, a problem critically discussed by Morgan Holmes (2008) or ask them to more actively resist such a system and dismiss heterosexuality or a heterosexual lifestyle (Smart, 1996). Rather, my aim is to explore how these women draw on and challenge norms and beliefs about heterosexuality and bodies when describing their experiences of vaginal reconstruction. In particular, I address how sociocultural norms induce a need for medical intervention in presenting the vagina as a minimum requirement for the enablement of (hetero)relational normality. This notion of ideal (hetero)relational normality acquires a corporeal dimension inasmuch as it affects and shapes the women's corporealities, i.e. their bodily ways of being and interacting with others in the world. At the same time such corporeal shapings reinforce and strengthen the notion of an ideal 
(hetero)relational normality and form understandings of sexual function and genitals. Finally, I address how the women in my study concurrently create space for resistance and re-negotiate the notion of ideal (hetero)relational normality and the norms it draws on; and suggest that an analysis of the women's treatment narratives contributes to critical discussion of genital modification and normative heterosexuality.

In addition, the article seeks to provide a deeper understanding of how these women account for their treatment decisions and present their ambivalence regarding these decisions in their narratives. While there so far only has been two attempts to transplant a uterus and none of these has resulted in pregnancy, ${ }^{1}$ the absence of a vagina is commonly treated either with surgery or by dilation of the vaginal dimple, i.e. vaginal reconstruction (Liao et al., 2006; Ismail-Pratt et al., 2007). However, research on what it is like to be diagnosed with and treated for congenital absence of the vagina in adulthood is rare within the humanities and social sciences as well as within feminist work (see, however, Boyle et al., 2005; Holt and Slade, 2003; Zeiler and Guntram, forthcoming). Previous studies have primarily focused on the ethics and medical management of children born with 'disordered sex development' (DSD), ${ }^{2}$ on parental experiences and on the affected persons' experiences as adults (Dreger, 1999; Feder, 2006; Gough et al., 2008; Holmes, 2008; Karkazis, 2008; Roen, 2008; Zeiler \& Wickstrom, 2009).

\section{Genital surgeries and normative heterosexuality: feminist perspectives}

Women's bodies and subjectivities, bodily modification and heterosexuality are recurrent topics in feminist research. There has been vigorous feminist debate concerning the beauty industry in general and cosmetic surgery in particular, and many scholars have examined women's narratives about these practices (see e.g. Bordo, 1997; Davis, 1995; Edmonds, this volume; Gagné \& McGaughey, 2002; Gimlin, 2007; Heyes, 2007; Morgan, 1991). In recent years there 
has been an increased interest in female genital cosmetic surgery (FGCS), which involves procedures 'that aim to change aesthetic (or functional) aspects of women's genitalia but that are not medically indicated' (Braun, 2010:1393). ${ }^{3}$ Critical examinations of these practices have indicated that they design bodies to fit normative sexual practices (Braun, 2005).

Closely connected to the above is feminist work on normative heterosexuality (M Jackson, 1984; S Jackson, 2006; Rubin, 1984; Seidman, 2005; Smart, 1996) which has highlighted the hierarchical organisation of sexuality in Western societies. Institutionalised normative heterosexuality is double-sided: it 'regulates those kept within its boundaries as well as marginalizing and sanctioning those outside them' (S Jackson, 2006:105). Along the same lines, empirical studies have shown that while young women attempt to negotiate meanings of traditional heterosexual patterns and practices, they nevertheless seem to uphold traditional views of femininity and sexuality (Allen, 2003; Harris et al., 2000; Maxwell, 2007; Stewart, 1999). Moreover, sexual hierarchies regulate sexual practice: there is 'one best way to do it, and [...] everyone should do it that way' (Rubin, 1984:283) and marital, reproductive sex acts are at the top of the hierarchy. Although alternative discourse do exist the 'coital imperative' is strong and dismisses sexual practices such as kissing, touching, oral and anal sex (and all other non-heterosexual practices) as preliminary, optional extras, or second-best substitutes for penile-vaginal intercourse (Gavey, McPhillips \& Braun, 1999; Jackson, 1984; McPhillips, Braun \& Gavey, 2001). In this way, the coital imperative limits understandings of sexual practice in a manner that may stabilize certain sexual desires and behaviours (Gavey, McPhillips \& Braun, 1999; Karkazis, 2008). Furthermore, it may strengthen links between gender identity, heterosexual practice and genitals (Braun \& Wilkinson, 2005; Kaler, 2006; Kraus, this volume). Critical assessments of success in vaginal reconstructions for people with intersex conditions indicate, for example, that a 'good' sized vagina is defined as one able to accommodate a 'normal' sized penis (Karkazis, 2008; Kessler, 1998). 
Yet scholars have also remarked on feminists' focus in discussions of heterosexuality. Carol Smart (1996) suggests that instead of being concerned with bad heterosex and with constituting the heterosexual woman as a victim, feminists should acknowledge that women might enjoy or want better heterosex. She argues that '...it is quite possible to acknowledge same of the benefits of living the heterosexual life-style and still seek to problematise the concept and category of heterosexuality'. What is required is a transgression of heterosexuality, not a denial of it (Smart, 1996:234). Stevi Jackson (2008:34) similarly argues that the 'ongoing negotiation of everyday, mundane, conventional sexual lives' has been left out of the 'polarized priorities between those pursuing anti-violence and exploitation agendas and those defending pleasure and diversity'. She suggests that it is precisely through understanding the patterns of sexual relations in people's everyday lives that we can clarify the taken-for-granted and habitual as well as gain an understanding of the celebration or devaluation of certain forms of sexual diversity.

\section{Vaginal agenesis: characteristics and treatment}

Vaginal agenesis (absence of the vagina) due to Mayer-Rokitansky-Küster-Hauser (MRKH) syndrome is found in about 1/4000-1/10,000 females (ACOG, 2002). The women diagnosed with this condition are genetically female and since neither the structure nor the function of the ovaries is affected undergo 'normal' pubertal development as regards secondary sex characteristics (i.e. breast development, hair growth and external genitalia). However, having no uterus or vagina they do not menstruate, are unable to conceive and may have difficulty in performing vaginal intercourse (Morgan and Quint, 2006).

Commonly, the condition is detected as a result of absent menstruation with most women undergoing treatment in late adolescence (ACOG, 2002). This is either in the form of surgery where a neo-vaginal space is created by using skin grafts or a section of intestine, or through 
dilation whereby the vaginal dimple is stretched with dilators graduating in size (Edmonds, 2003). In the European as well as in the North American context, surgical procedures have in recent years been criticised as inflicting unnecessary pain and scarring and it has become more common to only use dilators (Ismail-Pratt et al., 2007; Liao et al., 2006; Roberts et al., 2001).

\section{Material and methods}

This article presents data from 10 in-depth interviews with women who, in their teens, became aware that they did not have a vagina or that they only had parts of a vagina. ${ }^{4}$ The interviewees were all of Swedish origin and within the age range 18-26 at the time of interview. Seven of them had undergone surgery and had been advised to undertake post-operative dilation. Two others were advised to use dilators and the third was offered surgery but turned it down and was not offered dilators. All interviewees had been told that the vagina could be enlarged by penetrative intercourse and eight said they had had intercourse. The interviews were conducted in Swedish. They followed a semi-structured interview-guide designed to encourage the women to talk about their bodies and situation, their everyday interaction with others and their medical encounters. $^{5}$

In this article I use narrative analysis. I understand narratives as sequential and meaningful stories of personal experiences (Squire, 2008:43). They may include oneself and others and they may describe past, present or imagined events or experiences (Squire, 2008). Through narration people make sense of their experiences but also present themselves, their point of view, their perspective and their knowledge of the world in particular ways (Bruner, 2003). Narratives' contents and the ways in which they are told are understood as shaped by the socio-cultural context in which the narrative is told. They are created in a process of coconstruction in which the teller and the audience, whether real or imagined, explicitly or implicitly takes part (Riessman, 2008). 
In my analysis I focused both on how women accounted for their actions and decisions but also on the content of their interviews. I attended to how they positioned themselves and others as characters ordered in space and time in order to endow their narratives with meaning (Bamberg, 2004). This led me to explore how the interviewees juggled sometimes juxtaposed narratives (Bamberg 2004) and the assumptions about bodies, (hetero)sexual practice and relationships that were drawn on to make the narratives coherent (Adelswärd, 1997; Linde, 1986). In the following, all names of interviewees, doctors and others mentioned are fictive.

\section{Three treatment narratives}

My analysis identified three treatment narratives. In the first, the women describe their decisionmaking with regard to treatment and present their choice to undergo treatment as self-evident and unavoidable. In the second, the women tell of how they have dilated despite pain in order to maintain a normal sized vagina and how sexual practice becomes part of this maintenance work. In the third, the women depict their decision to cease dilation and question the results of treatment.

\section{Creating a body that works: intertwining treatment and (hetero)relational normality}

In the first narrative women present and account for their treatment decisions. They underscore their dissatisfaction with the present state of affairs (i.e. not having a vagina or having one considered too small) and present their wish to be 'normal' in the sense of being more like everyone else and having a body that 'works'. Linda says she chose surgery because she wanted everything to become as normal as possible: she remembers thinking 'normal is good!' and 'now it's not normal and it's not good!' Jenny, on the other hand, says that 'I totally does not mind being different in some way, but I do wanted it all to work as normally as possible'. This focus on a 'working' body is further underscored as the women describe medical encounters. Jenny says that her doctor talked about sex and relationships and explained that 'there are ways 
to make it work'. Veronica also exemplifies this focus by stating that her doctor 'gave the impression that everything wasn't completely screwed' and that 'it could work anyway'. While she acknowledges that decisions about surgery are based primarily on how interested you are 'in that kind of sex', she says that she definitely did not consider not having surgery: 'You still want to be as normal as possible' and 'you think about future sex', she explains. ${ }^{6}$

This first narrative shows that against a backdrop of norms and beliefs about heterosexual relationships and sexual practice, certain bodies are categorised as calling for modification, which creates a need for intervention. Moreover, in the light of medical progress and belief in medicine's capacity to create a body that 'works' in taken-for-granted heterosexual practices, treatment is positioned as the self-evident option. ${ }^{7}$ Jessica, for example, explains that when she found out about her condition she had recently met a man and explains that 'I couldn't have sex at that time and I felt "Why would he ever want me?"'. She says that she wanted surgery since she wanted to 'at least appear like everyone else' and that 'it was self-evident to want to be like everyone else'. In the following this is further exemplified as she tells of her appointments with the gynaecologist and the plastic surgeon:

Interviewer: And then you saw Doctor Svensson?

Jessica: Yes.

Int: $\quad$ And what happened?

$J: \quad$ Gosh, I’ve seen Doctor Svensson so many times I mix it all up.

Int: $\quad$ Oh you do? That doesn't really matter. But these first visits, before the surgery, do you remember what you talked about or what... ${ }^{8}$ ?

$J: \quad$ She examined me, of course, and Doctor Andersson [i.e. the plastic surgeon] was there too and they explained how the surgery would be performed and I could decide whether I wanted to use skin from the thighs or the buttocks. 
[Omission of speech. The interviewer mentions that the doctors will not be able to identify Jessica and the focus shifts somewhat until the researcher asks the following question]

Int: Did you talk about any other treatments or was surgery...?

$J: \quad$ No...

Int: Was it the only option? Kind of?

$J: \quad$ Yeah... Of course I wasn't forced to do it. But of course I wanted to. So we

didn't talk about any options. That was probably... that was about it.

Int: What was it that felt so self-evident about it?

$J: \quad$ About surgery?

Int: Wanting to have... - choosing surgery?

$J: \quad$ Yes but the thing is, you want to be like everyone else.... It's really all about that. And you do want to have... like, get the chance to have a normal life. If you want to...Something like that.

In this excerpt surgery is in focus. Jessica does not speak of discussing options and presents surgery as motivated by the desire 'to be like everyone else'. As she puts it, 'It's really all about that.' Here Jessica can be seen to draw on a heteronormative explanatory system of common sense (Linde 1986) in order to account for her decision to have surgery. This system of assumptions about the world - a system used to make events and evaluations coherent (Linde, 1986:188) - is further revealed as Jessica underscores that she 'of course' was 'not forced to do it', but that she nevertheless wanted to. She also underscores the taken-for-grantedness of surgery as she uses 'you' instead of 'I' when explaining her reasons: 'you want to be like everyone else' and 'you do want' to get the chance of a normal life. Within this explanatory system of common sense the decision to have surgery is presented as more or less uncontroversial, and there seems to be little space for discussing options. 
As women account for their treatment decisions they connect their focus on a 'working' body and a 'working' sex life to present or future relationships. Anna says that '.... sex...it didn't work. Not to do it the normal way anyhow.' She and her first boyfriend talked a lot about what to do but it was not until she met her second boyfriend that she saw a gynaecologist.

Interviewer: So that was about two years after you found out about it [not having a uterus]? Anna: $\quad$ Yes... because then I felt, kind of, that something had to happen. Because it's really not possible to have a boyfriend in the long run without, like, having sex at all. (Int: No... ?) Not with the ones I met anyhow [laughs].

Int: $\quad$ Did it seem like an alternative to you?

A: $\quad$ It was more like 'well, whatever... ', it wasn't vital or anything... to me. But they felt... - so then I felt 'I can check it out, at least'. Because I really would like to know what it was that... why it didn't work. So then I went there and they [the doctors] did the first surgery.

For Anna 'sex' is understood as intercourse and is crucial in heterosexual relationships. These norms position a 'normal' vagina as required and create a need for medical advice. That is, in the light of socio-cultural assumptions about sex and relationships, which endow certain body parts with particular significance, knowledge of the absence of a vagina results in a need of medical intervention. The excerpt shows how beliefs about present and future partners position these persons as of particular importance in treatment decisions. This is brought out where Anna underscores with laughter that one cannot have a relationship without sex, at least not with the kind of men she has met. Nevertheless, this remark does imply a certain questioning. In saying that sex, i.e. intercourse, is important at least to the men that she has met, she implicitly acknowledges that this might not be the case with all men. And, more importantly, she adds 
that although she wanted to investigate what her condition involved and what surgery would entail, this kind of sex was not 'vital' to her.

This first narrative corresponds to the idea that normative heterosexuality may regulate those within its boundaries (S Jackson, 2006), reinforcing a 'coital imperative' (M Jackson, 1984). Here the women draw on a set of socio-cultural norms and beliefs in the light of which treatment is presented as the obvious choice - not only because it can make your body more like everyone else's but also, and indeed chiefly, because it enables long-term relationships with male partners, i.e. provides (hetero)relational normality. Importantly, this notion of (hetero)relational normality has a corporeal dimension. It reflects certain assumptions about 'normal' female genitals - and about the possibilities of creating such genitals through treatment - that shape these women's corporeal subjectivities. But this entanglement of ideal (hetero)relational normality and medical intervention, which results in specific surgical and bodily shapings, not only informs understandings of female 'corporeal requirements' but also involves narrow views of male partners' bodies, expectations and desires, as becomes clearer in the analysis of the second narrative.

\section{Maintaining vaginal size: endurance and the conflation of sex and maintenance}

In the second narrative women tell of the maintenance work required to increase and preserve the size of the vagina, either by use of dilators or by having intercourse. ${ }^{9}$ Drawing on the same socio-cultural norms and beliefs as the first narrative, the main point here is that despite pain and emotional effort, maintenance is endured because it gets better over time and will make 'sex' work. Jessica describes what it was like to use the dilators after having had surgery:

Jessica: And then I had to... Since they'd created a vagina I had to use, like, dilators. And I had to use them several times a day, and it felt very difficult and it hurt. And I 
felt that you had to force it [the dilator]. Yeah, in the beginning it was really tough, I remember. And I was really upset and cried because... - yeah, because it hurt and it was hard and I thought, kind of, 'Is it going to go on like this forever?' But then again you do it more often in the beginning, to stretch it.

Int: $\quad$ So how did you feel about this treatment? What was it like to use the dilators? Could you describe it?

$J: \quad$ Yeah... in the beginning it was tough and it felt... strange. (Int: Mmm) But it did get better and better all the time.

Int: $\quad$ So for how long did you use them?

$J: \quad$ Well, ... I'll be using them for the rest of my life.

In this excerpt Jessica presents herself as a person who has endured the pain of maintenance. Although it was 'really tough' in the beginning and she 'was really upset and cried', she indicates that her endurance eventually paid off. Yet, although she says that it got better and better, Jessica at the same time points out that maintenance is a lifelong commitment. In the light of the first narrative, this commitment can be interpreted as necessary for preserving (hetero)relational normality as well as for positioning oneself in relation to others within the prevailing sexual hierarchies.

However, maintenance does not only involve dilators. All the women indicate that they have been told by their doctors that dilators are not necessary if they have sex (i.e. penilevaginal intercourse). Elsa, for example, says that she has been told that 'if you meet a man, you don't have to use them'. But if the relationship ends, Elsa explains, you have to use them again because 'otherwise it'll grow back together. It will. And then there's nothing more you can do about it, they've said.' Patricia touches upon the same topic as she describes how she sometimes 
felt that she had to have sex although she did not feel like it, and remembers thinking 'OK, I suppose I might as well do it [have intercourse] so as to do something about it [vaginal size].'

In presenting the use of dilators as unnecessary if one enters into a relationship, the women indicate not only the assumed sexual practice in (heterosexual) relationships, but also how sex in the sense of vaginal penetration becomes a part of maintenance. Hence the second narrative reveals not only how a notion of ideal (hetero)relational normality forms the women's corporeal experiences of, and interactions with, their own bodies as they undertake sometimes painful dilation, but also how this notion forms their physical interactions with partners, where intercourse is presented as the only substitute for the use of dilators. That is, treatments are directed towards 'sex' but sex also becomes treatment. Maintenance becomes a part of the 'ongoing negotiation of everyday, mundane, conventional sexual lives' (S Jackson, 2008:34) and positions these women's bodies as sites for the maintenance of (hetero)relational normality and their male partners' bodies as instruments for this. Hence maintenance may not only strengthen norms and beliefs about vaginal size and assumed sexual practice, but likewise reinforce sociocultural norms about the size and function of male genitals and assumptions about male partners' sexual desires and expectations.

Refusing maintenance and questioning results: re-negotiations of (hetero)relational normality The third narrative has a different tone than the previous two. Although it takes its starting point in the same assumptions, the women here present a different view of treatment. This becomes clear as they tell of how they have ceased to dilate and articulate their doubts concerning the results of treatment. This narrative contains a certain questioning as the interviewees point out that although they wanted a larger vagina they did not by any means like the maintenance work required and 'wanted it to be over with right away', as Anna said. The majority also say that they have not dilated as much as 'you should' because of the pain and effort it involves. Anna 
also says that she knows she is supposed to use the dilators regularly, but because of the pain she only uses them when she 'has to', i.e. the days before she has a doctor's appointment. Maria likewise says that she hardly ever used the dilator. She was told that 'you were supposed to do it 20 minutes every day for about 10 months, or something like that' and she found this very 'difficult to deal with'- both psychologically and physically because of the pain. Especially, she says, she finds it hard that she 'has to create something others already have got', adding that 'it hurts a lot too'. An excerpt from Linda's interview further exemplifies how the women question whether maintenance is really worth the effort.

But I think - or rather I know, because a while ago I read a note from my diary that I'd written after I'd had surgery - that I obviously found it more difficult afterwards than I'd ever imagined it could be. It hurt a lot more afterwards and it was more difficult and tricky to keep the dilator, which would keep it open, in place and everything. And I know that Doctor Johnson talked about this, but still I hadn’t at all expected it. You think more about the operation and that it'll hurt right afterwards and that it'll be quite all right after that, but it kept on and it was really difficult and it still is, kind of - not as bad but still a bit difficult, yeah...

Thus on the basis of her diary note Linda makes the point that maintenance using dilators was more difficult than she had imagined it to be, despite her doctor's warning. Linda connects the difficulties to her cessation of dilation. While acknowledging that dilation 'of course' gets easier and hurts less with the passage of time, she later on in the interview indicates that 'to be honest, it's easy to fall into doing it less intensely' because it takes a lot of time and 'still hurts quite a lot'. 
In this narrative women also de-emphasise the significance of vaginal size. Some of them do so by underscoring that male partners do not seem to notice any difference. Jenny, for example, says that she only uses the dilators once in a while, perhaps not as often as she should. But she does not see anything 'too dangerous' in this, and says that her boyfriend, whom she has not yet told, does not seem to have noticed that her vagina has been surgically created. Joanna similarly says that to her knowledge no man has been able to tell that her vagina has been surgically created. Possibly, Joanna adds, the man could start to wonder about the scars on her thighs from the skin grafts, but so far she has made sure to turn the lights off and thus there has been no comment. Other women indicate that men do not seem to care as much about the vagina as they had expected. Maria explains that you might have to be careful when having sex and that you might need lubricants, but she has found that men are very accepting and understanding 'when it comes to these things', which she had not expected. As in the previous narratives, male partners have a central role - but, as these examples reveal, the third narrative presents a different view of male partners' expectations and reactions. ${ }^{10}$ Thus this narrative indicates that a 'normal' sized vagina is not so important for relational normality after all.

Finally, in this third narrative women also question the results of treatment. Patricia says that she found it hard to know how much she had to dilate in order to make her vagina 'normal' sized. Searching the Internet, she found out that a normal sized vagina is 10 to 14 centimetres long, and she says 'I thought "Oh my god, I don't have anything like that! Will this work?!" But it did'. ${ }^{11}$ Here, Patricia can be seen as implicitly questioning the results of dilation and the importance of vaginal length by underscoring that although she previously felt unsure whether her vagina would 'work', it all turned out okay. In contrast, Joanna questions whether treatment provides the desired results. She explains that she wanted to get the surgery over with as quickly as possible in order to be able to have sex, but after the surgery sex became difficult. At that point, she says, she did not feel like having sex any more but felt she had to 'because otherwise 
it'll just get smaller and then you'll have done it all for nothing'. This 'became somewhat of a dilemma', Joanna explains. She also comments on her lack of sensation during sex: perhaps she 'shouldn't be able to feel anything' because the vagina 'isn't real'. Hence treatment may create a 'normal' sized vagina but sex may still be more difficult than expected. And although she now has a vagina, Joanna describes it as not being 'real' and indicates her uncertainty as to whether such a vagina is supposed to provide the sensations that she seems to have expected.

The interviewees who did not have surgery remark even more explicitly on the results of treatment. Esther explains that sex can be painful, especially if the man has a large penis, and says that she was considering surgery in the hope that it would make sex more pleasurable. Still, in the excerpt below she expresses her criticism of the way in which she was told that surgery would make everything fine.

Interviewer: What was it that was going to be fine?

Esther: It'd get really easy to have sex and then I'd be more like everyone else, that was kind of the way I understood it. When I look back on it now I say to myself: 'Yeah, but why did they only tell me about that side of it?' There was never anything about it not turning out that good. Because, I mean, when you read stuff on the Internet, you, like, find that it can go wrong and if you take skin from the thigh it might start to grow hair! I mean, then you're certainly not like everyone else, are you?!? Things like that were never even mentioned, but at the same time - no, I don't know, but at least they didn't try to talk me into it. They told me to wait. And I felt that was good. Because if they'd... if they' $d$ been more persistent, telling me to have it done, then I'd have had it done... without knowing what I was getting myself into. 
Esther presents herself as a person who could have been talked into having surgery without knowing what she was getting herself into. Nevertheless, information about possible outcomes of surgery made it possible for her to question how surgery had been presented to her. It made her realise that surgery may not make you more like everyone else: it may indeed result in greater differences, for instance if the grafted skin starts to grow hair. Like Esther, Maria questions the results of surgery but also the need for a vagina. In her view doctors might not even consider that not everyone needs a vagina, for instance if you are homosexual. Or, she says, some women might not even feel anything from vaginal intercourse after having had surgery. 'If so, what's the purpose of creating a vagina?' Maria wonders, and adds that it 'might not even matter'. Here Maria presents an awareness of how norms and beliefs about bodies, sexual practice and relationships shape medical interventions. Her questioning of treatment practices that do not necessarily result in a better sexual experience for the woman can thus be interpreted as an opposition to the corporeal shapings in accordance with enacted norms that the absence of a vagina is believed to call for.

In the third narrative women present contrasting perspectives on the significance of the vagina and the meaning of sexual function. Here the body is not presented as a site for modification and maintenance but as a site for resistance. In telling of refusing painful dilation and questioning the results of vaginal reconstruction, women pave the way for critical reflection about sexual practices, male partners' expectations and medical prospects that can make possible a re-evaluated and expanded understanding of (hetero)relational normality.

\section{Concluding discussion}

The notion of ideal (hetero)relational normality outlined above draws on enacted socio-cultural norms concerning bodies, sexual function, heterosexual practices and heterosexual relationships. In this it corresponds to the extensive feminist discussion of normative 
heterosexuality (M Jackson, 1984; S Jackson, 2006; Rubin, 1984; Seidman, 2005; Smart, 1996). Importantly, the notion of ideal (hetero)relational normality has a distinct bodily dimension. It shapes the women's corporeal subjectivities as it positions certain body parts as particularly desirable. It is furthermore expressed and reinforced through the bodily shapings that the women undergo in order to create a body that 'works'. The knowledge of the absence of a vagina thus gives rise to a need for treatment to create a body that fits the ideal - a need that informs understandings of 'functioning' bodies and 'functioning' sexual practice. Hence sociocultural norms shape corporealities and corporeal shapings express and consolidate sociocultural norms.

This conclusion corresponds with Virgina Braun's comment that FGCS along with other genital surgeries is part of an 'ongoing social and material construction of (gendered) genital meaning and appearance' (Braun, 2005:FN3). However, the connection between vaginal reconstructions in adult women diagnosed with congenital vaginal agenesis and FGCS has rarely been examined studies of genital surgeries (see e.g. Braun, 2009; Tiefer, 2008). Likewise, such vaginal reconstructions have been left without scrutiny in discussions of treatment for DSD conditions (see, however, Boyle, Smith \& Liao, 2005). This lack of discussion is unfortunate. If vaginal reconstructions in women with vaginal agenesis are not subjected to critical examination within the framework of FGCS and DSD treatment, such reconstructions may be understood as uncontroversial in comparison to other genital surgeries (see also Kraus, this volume). If there is a failure to acknowledge that these practices draw on similar sociocultural norms and beliefs, vaginal reconstructions in women with vaginal agenesis will be categorised as more socially and medically justified than FGCS (see e.g. Braun, 2009:234). I suggest that the contribution of critical examinations of these particular reconstructions lies in how they expand our understanding of possible motives and reasons behind bodily modification. Here the focus is not, as in FGCS (Braun, 2005; 2009), on aesthetic improvement 
or enhanced function and increased pleasure, but on the creation and maintenance of a 'working' vagina inasmuch as such a vagina is accorded special significance in (hetero)relational normality.

The notion of ideal (hetero)relational normality is reinforced through the bodily maintenance work to which the women commit themselves. This work shapes the women's corporealities, requiring women to undertake most often painful dilation of the vagina in order to increase and maintain its size. As intercourse becomes a part of this bodily maintenance work, the notion of ideal (hetero)relational normality also affects the women's sexual interactions with male partners. This conflation of intercourse and maintenance gives male partners a crucial role in the dilation of the medically created vagina. Maintenance work thus positions the female body as a site for maintenance and the male body as an instrument in this work. In this manner, maintenance consolidates socio-cultural norms concerning the size and function of female and male genitals - norms which, when enacted, may contribute to the stabilisation of certain sexual behaviours (Karkazis, 2008).

At first the notion of an ideal (hetero)relational normality seemed to provide little space for questioning or resistance. However, two implicit forms of resistance nevertheless emerged. First, the women's refusal of maintenance work positioned the body as a site for resistance where the way in which ideal (hetero)relational normality functioned as a backdrop to treatment decisions and maintenance work could be challenged. Second, the women's questioning of medical results allowed re-negotiation of the possibilities of medical interventions and reflection about the specificity of their sexual subjectivities. Without denying heterosexuality (see Smart, 1996), alternative interpretations of sexual practice and heterosexual relationships were thus made possible, which in turn expanded understandings of (hetero)relational normality and its bodily requirements. 
The way in which the women 'juggle' the three narratives reveals the complexity of living with vaginal agenesis and of undergoing of vaginal reconstruction. More importantly, the identification of the corporeal dimensions of (hetero)relational normality in their narratives offers a valuable vantage-point for feminist discussion of how to transgress heterosexuality (Smart, 1996) and of peoples continuous efforts to negotiate sexuality and sexual practice in everyday life (S Jackson, 2008). These narratives highlight how socio-cultural norms result in corporeal modification and maintenance work which form the women's corporeality and inform understandings of female bodies and functions, but also how such work and understandings can be re-negotiated in everyday life. Furthermore, they show how the male body is assigned meaning in accordance with the corporeal shapings of female bodies, thus indicating the role of ideal (hetero)relational normativity in shaping men's ways of being and interacting in the world.

\section{Acknowledgements}

I would like to express my deepest gratitude to the 10 interviewees who shared with me their stories about their lives. I would also like to thank those doctors and bloggers who helped me recruit interviewees for their collaboration.

\section{Notes}

1. In September 2012 a research team at Sahlgrenska University Hospital, Sweden, performed two uterus transplantations from mother to daughter (Svahn, 2012). In 2011 it was reported that a uterus had been transplanted in Turkey and that the recipient had started menstruating (Allen \& Macrae, 2012).

2. Medically, DSD includes congenital conditions in which the development of chromosomal, gonadal or anatomic sex is atypical (Lee et al., 2006). However, there is an on-going debate 
concerning how to use the concept and concerning whether DSD or intersex is the most appropriate (see e.g. Feder \& Karkazis, 2008; Holmes, 2011). In this article I use neither, since they are not used by my interviewees.

3. FGCS includes 'labia minora reductions, vaginal tightening ("rejuvenation"), labia majora “augmentations", pubic liposuction (mons pubis, labia majora), clitoral hood reductions, hymen “reconstruction", perineum "rejuvenation", and "G-spot amplification" ' (Braun, 2010:1393).

4. Seven of them said that they had MRKH syndrome but only three have had this diagnosis confirmed. The remaining three interviewees have no name for their condition.

5. Owing to the rareness of the condition and the lack of patient groups, my recruitment of participants was opportunistic: five were recruited though a plastic surgeon at a university hospital in Sweden, four through blogs, one through her having contacted me as she had found an ad about the project online. The study followed the ethical guidelines of the Swedish Research Council (2002) and was approved by the regional ethical review board. The interviewees were all informed that they could end the interview at will and that the data gathered would be treated confidentially. All gave their informed consent. The interviews lasted about an hour; they were recorded and transcribed verbatim.

6. The women's focus on function could be interpreted as stemming from a lack of resources for 'pleasure-talk' among young women in general (see Holland, 2004; Stewart, 1999).

7. That treatment is regarded as the obvious choice comes out most strikingly in the interviews with the seven women who had undergone surgery. Whether they wanted to get surgery over with as soon as possible or preferred to postpone it, they all emphasise that they would have had it sooner or later. Though the other three women had not undergone surgery, they nevertheless presented it as a possibility if vaginal dilation by means of dilators or intercourse should not be successful.

8. Here '...' represents paus or hesitation. 
9. The women who had undergone surgery performed dilation post-operatively. The women who had not had surgery presented dilation as a substitute for it.

10. However, while the women here present the vagina as less significant than in the previous narratives, they do not focus chiefly on pleasure but on function.

11. In contrast to the vaginal lengths Patricia describes, Lloyd, Crouch, Minto et al. (2005:645) state, in their examination of variations in genital dimensions of normal women, that 'the mean vaginal length was at $9.6[1.5] \mathrm{cm}$ with a wide range varying from 6.5 to $12.5 \mathrm{~cm}$.'

\section{References}

ACOG (2002) ACOG committee opinion no247, July 2002. Nonsurgical diagnosis and management of vaginal agenesis. International Journal of Gynecology \& Obstetrics 79(2): 167-170.

Adelswärd V (1997) Berättelser från älgpassen. Om metoder för att analysera jaktberättelsers struktur, poäng och sensmoral. In: Hydén L-C and Hydén M (eds) Att studera berättelser: samhällsvetenskapliga och medicinska perspektiv. Stockholm: Liber, pp $198-235$.

Allen L (2003) Girls want sex, boys want love: resisting dominant discourses of (hetero)sexuality. Sexualities 6(2): 215-236.

Allen V and Macrae (2012) The world's first womb transplant: Landmark surgery brings hope to millions of childless women - and it could happen in Britain soon. Available at: http://www.dailymail.co.uk/news/article-2150178/The-worlds-womb-transplantLandmark-surgery-brings-hope-millions-childless-women--happen-Britain-soon.html (accessed 31 August 2012).

Bamberg M (2004) Considering counter narratives. In: Andrews M and Bamberg M (eds) Considering counter narratives: narrating, resisting, making sense. Amsterdam: J. Benjamins, pp.351-371. 
Bordo S (1997) Twilight zones: the hidden life of cultural images from Plato to O.J. Berkeley: University of California Press.

Boyle ME, Smith S and Liao L-M (2005) Adult Genital Surgery for Intersex: A Solution to What Problem? Journal of Health Psychology 10(4): 573-584.

Braun V (2005) In Search of (Better) Sexual Pleasure: Female Genital “Cosmetic” Surgery. Sexualities 8(4): 407-424.

Braun V (2009) 'The Women Are Doing It for Themselves': The Rhetoric of Choice and Agency around Female Genital ‘Cosmetic Surgery.' Australian Feminist Studies 24(60): 233-249.

Braun V (2010) Female Genital Cosmetic Surgery: A Critical Review of Current Knowledge and Contemporary Debates. Journal of Women's Health 19(7): 1393-1407.

Braun V and Wilkinson S (2005) Vagina equals woman? On genitals and gendered identity. Women's Studies International Forum 28(6): 509-522.

Bruner JS (2003) Making stories: law, literature, life. Cambridge, Mass.: Harvard University Press

Davis K (1995) Reshaping the female body: the dilemma of cosmetic surgery. New York: Routledge.

Dreger AD (1999) Intersex in the age of ethics. Hagerstown, M.D.: University Pub. Group.

Edmonds A (this volume) Beyond social constructionism? The biologisation of sex and beauty in cosmetic surgery. Feminist Theory

Edmonds DK (2003) Congenital malformations of the genital tract and their management. Best Practice \& Research Clinical Obstetrics \& Gynaecology 17(1): 19-40.

Feder EK (2006) 'In Their best interest': Parents' Experience of Atypical Genitalia. In: Parens E (ed.), Surgically shaping children: Technology, ethics, and the pursuit of normality. Baltimore, Md.: Johns Hopkins University Press, pp. 189-210. 
Feder EK and Karkazis K (2008) What's in a Name? The Controversy over “Disorders of Sex Development." The Hastings Center Report 38(5): 33-36.

Gagné P and McGaughey D (2002) Designing Women. Gender \& Society 16(6): 814 -838.

Gavey N, McPhillips K and Braun V (1999) Interrupts Coitus: Heterosexuals Accounting for Intercourse. Sexualities 2(1): 35-68.

Gimlin D (2007) Accounting for Cosmetic Surgery in the USA and Great Britain: A Crosscultural Analysis of Women's Narratives. Body \& Society 13(1): 41-60.

Gough B, Weyman N, Alderson J, Butler G and Stoner M (2008) “They did not have a word”: The parental quest to locate a "true sex" for their intersex children. Psychology \& Health 23(4): 493-507.

Harris A, Aapola S and Gonick M (2000) Doing it Differently: Young Women Managing Heterosexuality in Australia, Finland and Canada. Journal of Youth Studies 3(4): 373388.

Heyes CJ (2007) Self transformations: Foucault, ethics, and normalized bodies. Oxford: Oxford University Press.

Holland J et. al. (2004) The male in the head: young people, heterosexuality and power. London: Tufnell.

Holmes M (2008) Intersex : a perilous difference. Selinsgrove Pa.: Susquehanna University Press.

Holmes M (2011) The Intersex Enchiridion: Naming and Knowledge. Somatechnics 1(2): $388-411$.

Holt RE and Slade P (2003) Living with an incomplete vagina and womb: an interpretative phenomenological analysis of the experience of vaginal agenesis. Psychology, Health \& Medicine 8(1): 19 . 
Ismail-Pratt IS, Bikoo M, Liao L-M, Conway GS and Creighton SM (2007) Normalization of the vagina by dilator treatment alone in Complete Androgen Insensitivity Syndrome and Mayer-Rokitansky-Kuster-Hauser Syndrome. Human Reproduction. 22(7): 2020-2024. Jackson M (1984) Sex research and the construction of sexuality: A tool of male supremacy? Women's Studies International Forum 7(1): 43-51.

Jackson S (2006) Interchanges: Gender, sexuality and heterosexuality The complexity (and limits) of heteronormativity. Feminist Theory 7(1): 105-121.

Jackson S (2008) Ordinary Sex. Sexualities, 11(1-2), 33-37.

Kaler A (2006) Unreal Women: Sex, Gender, Identity and the Lived Experience of Vulvar Pain. Feminist Review 82: 50-75.

Karkazis K (2008) Fixing sex: intersex, medical authority, and lived experience. Durham, N.C.: Duke University Press.

Kessler SJ (1998) Lessons from the intersexed. New Brunswick, N.J.: Rutgers University Press. Kraus C (this volume) Hypospadias Surgery in a West African Context: The Surgical (Re-) construction of What?. Feminist Theory

Lee PA, Houk CP, Ahmed SF and Hughes IA (2006) Consensus Statement on Management of Intersex Disorders. Pediatrics 118(2): 488-500.

Liao L, Doyle J, Crouch N and Creighton S (2006) Dilation as treatment for vaginal agenesis and hypoplasia: a pilot exploration of benefits and barriers as perceived by patients. Journal of Obstetrics and Gynaecology: The Journal of the Institute of Obstetrics and Gynaecology 26(2): 144-148.

Linde C (1986) Private stories in public discourse: Narrative analysis in the social sciences. Poetics 15(1-2): 183-202.

Lloyd J, Crouch NS, Minto CL, et al. (2005) Female genital appearance: 'normality’ unfolds. BJOG: An International Journal of Obstetrics \& Gynaecology, 112(5): 643-646. 
Maxwell C (2007) “Alternative” Narratives of Young People's Heterosexual Experiences in the UK. Sexualities 10(5): $539-558$.

Morgan EM and Quint EH (2006) Assessment of Sexual Functioning, Mental Health, and Life Goals in Women with Vaginal Agenesis. Archives of Sexual Behavior 35(5): 607-618. Morgan KP (1991) Women and the Knife: Cosmetic Surgery and the Colonization of Women's Bodies. Hypatia 6(3): 25-53.

Riessman CK (2008) Narrative methods for the human sciences. London: Sage.

Roberts CP, Haber MJ and Rock JA (2001) Vaginal creation for müllerian agenesis. American Journal of Obstetrics and Gynecology 185(6): 1349-1353.

Roen K (2008) 'But We Have to Do Something': Surgical ‘Correction’ of Atypical Genitalia. Body \& Society 14(1): 47-66.

Rubin G (1984) Thinking Sex: Notes for a Radical Theory of the Politics of Sexuality. In: Vance CS (ed) Pleasure and danger: exploring female sexuality. Boston: Routledge \& Kegan Paul.

Seidman S (2005) From the Polluted Homosexual to the Normal Gay: Changing Patterns of Sexual Regulation in America. In: Ingraham C (ed.), Thinking straight. The Power, the Promise and the Paradox of Heterosexuality. New York: Routledge, pp.39-62.

Smart (1996) Desperately Seeking the Post-heterosexual woman. In: Holland J and Adkins L (eds) Sex, sensibility, and the gendered body. New York: St. Martin's Press.

Squire C (2008) Experience-centered and culturally-oriented approaches to narrative. In: Andrews M, Squire C and Tamboukou M (eds) Doing narrative research. Thousand Oaks, Calif.: Sage, pp.41-63.

Stewart FJ (1999) Femininities in Flux? Young Women, Heterosexuality and (Safe) Sex. Sexualities 2(3): $275-290$. 
Svahn (2012) World unique uterus transplantation performed in Gothenburg. Avaliable at: http://www.sahlgrenska.gu.se/english/news_and_events/news/News_Detail/worldunique-uterus-transplantation-performed-in-gothenburg-.cid1097607

Swedish Research Council (2002) Forskningsetiska principer inom humanistisksamhällsvetenskaplig forskning. Stockholm: Vetenskapsrådet. Available at: http://www.cm.se/webbshop_vr/pdfer/etikreglerhs.pdf.

Tiefer L (2008) Female Genital Cosmetic Surgery: Freakish or Inevitable? Analysis from Medical Marketing, Bioethics, and Feminist Theory. Feminism \& Psychology, 18(4): 466-479.

Zeiler, Kristin and Lisa Guntram (forthcoming) 'Excorporation, Affect and Sexed Embodiment as a Style of Being: Examining Young Women's Experiences of Coming to Know That They Have No Womb and No or a 'Small' Vagina', in: Zeiler K and Folkmarson Käll L (eds) Feminist Phenomenology and Medicine. New York: State University of New York Press.

Zeiler K and Wickstrom A (2009) Why do "we" perform surgery on newborn intersexed children?: The phenomenology of the parental experience of having a child with intersex anatomies. Feminist Theory 10(3): 359-377. 